\title{
Correlation of Antenatal Umbilical Cord Coiling Index with Perinatal Outcome
}

\author{
${ }^{1}$ Ruchi Monga, ${ }^{2}$ Jai K Goel, ${ }^{3}$ Sipra Bagchi, ${ }^{4}$ Shanti Sah, ${ }^{5}$ Ruchica Goel
}

\begin{abstract}
Aim: To study the association between antenatal umbilical cord coiling index $(\mathrm{aUCl})$ and perinatal outcome.

Materials and methods: This prospective study was conducted on 100 patients. The aUCl between gestational age 28 and 42 weeks was calculated by color Doppler as the reciprocal of the distance between a pair of coils. It was then correlated with the following pregnancy outcomes: mode of delivery, preterm delivery, birth weight, meconium staining, Apgar score at 1 and 5 minutes, and neonatal intensive care unit (NICU) admissions. Hypocoiled cords were those having umbilical cord coiling index (UCI) less than 10th percentile and hypercoiled cords were those having $\mathrm{UCI}>90$ th percentile. The results were statistically analyzed by chi-square test.
\end{abstract}

Results: The mean UCl was $0.61 \pm 0.16$. The hypocoiled umbilical cords $(\mathrm{UCl}<10$ th percentile) were significantly associated with low birth weight, meconium staining, low Apgar score at 1 minute, and increased NICU admissions with a p-value $<0.05$.

Conclusion: Hypocoilled cords are significantly associated with adverse perinatal outcome.

Keywords: Hypocoiled umbilical cords, Perinatal outcome, Umbilical cord coiling index.

How to cite this article: Monga R, Goel JK, Bagchi S, Sah S, Goel R. Correlation of Antenatal Umbilical Cord Coiling Index with Perinatal Outcome. J South Asian Feder Obst Gynae 2018;10(2):127-130.

Source of support: Nil

Conflict of interest: None

Date of received: 15 March 2018

Date of acceptance: 20 April 2018

Date of publication: July 2018

\section{INTRODUCTION}

The primary objective of antenatal and intrapartum fetal surveillance both in early and late pregnancy is to prevent fetal death. One of the most important parts

\footnotetext{
${ }^{1}$ Junior Resident, ${ }^{2}$ Professor and Head, ${ }^{3,4}$ Assistant Professor

${ }^{5}$ Senior Resident

${ }^{1-5}$ Department of Obstetrics and Gynecology, Shri Ram Murti Smarak Institute of Medical Sciences, Bareilly, Uttar Pradesh India

Corresponding Author: Ruchi Monga, Junior Resident Department of Obstetrics and Gynecology, Shri Ram Murti Smarak Institute of Medical Sciences, Bareilly, Uttar Pradesh India, Phone: +919458705951, e-mail: ruchimonga.hld@gmail.com
}

of the fetoplacental unit is the umbilical cord. It is now being studied in predicting the perinatal outcome. The cord and its constituent tissues, an outer layer of amnion, porous Wharton's jelly, two arteries and one vein, are designed to provide and maintain blood flow to the developing fetus. ${ }^{1}$

A coil is defined as a complete $360^{\circ}$ spiral course of umbilical vessels around the Wharton's jelly. The origin of umbilical cord coiling is unknown. Hypotheses include fetal movements, active or passive torsion of the embryo, differential umbilical vascular growth rates, fetal hemodynamic forces, and the arrangements of muscular fibers in the umbilical arterial wall. ${ }^{2-4}$

The umbilical cord coiling index is calculated by dividing the total number of coils by the total length of the cord immediately after delivery. ${ }^{5-8}$ Antenatal UCI is calculated as a reciprocal value of the distance between a pair of coils measured in $\mathrm{cm}$ from inner edge of an arterial or venous wall to the outer edge of next coil along ipsilateral side of umbilical cord, direction being from placental end to the fetal end measured by Doppler ultrasound. The objective of this study is to correlate antenatally the UCI and perinatal outcome.

\section{MATERIALS AND METHODS}

This prospective study was conducted on 100 patients recruited from the Department of Obstetrics and Gynaecology in collaboration with Department of Radiodiagnosis, Shri Ram Murti Smarak Institute of Medical Sciences, Bhojipura, Bareilly, India, after obtaining necessary approval of the ethical committee. After taking informed consent, a detailed history and clinical examination was done on 100 patients with gestational age $>28$ weeks, singleton pregnancy without any medical or obstetric complications, and a live fetus.

Hypocoiled or hypercoiled umbilical cords were those with corresponding coiling index values $<10$ th or $>90$ th percentiles respectively. The relationship between UCI and perinatal outcome was evaluated. Correlation of hypocoiling and hypercoiling with the perinatal outcome was based on the variables, such as mode of delivery, preterm delivery, birth weight, meconium staining, Apgar score, and NICU admission.

The statistical analysis was done using Statistical Package for the Social Sciences version 18 statistical 
analysis software. The test of statistical significance that was used to analyze the parameters was chi-square test.

\section{RESULTS}

The total number of cases studied was 100 . The maximum patients were in the age group between 21 and 25, i.e., 51 cases. The number of primigravida and multigravida was almost equal, i.e., 51 and 49\% respectively. The distribution of cord UCI in the study population is presented in Table 1.

Depicted in Table 2 is the correlation between mode of delivery, preterm delivery, and birth weight of the neonate

Table 1: Distribution of UCI

\begin{tabular}{ll}
\hline UCI & Neonate \\
\hline Normal & 81 \\
Hypocoiling & 9 \\
Hypercoiling & 10 \\
\hline Total & 100 \\
\hline
\end{tabular}

with UCI. Majority of patients delivered vaginally, i.e., $80 \%$ followed by lower segment cesarean section (LSCS) in $20 \%$ cases. However, no statistical significance of UCI with mode of delivery was observed.

Among 100 mothers recruited, 17 had preterm delivery, out of which 13 had normocoiling, 3 hypocoiling, and 1 hypercoiling. No statistically significant association was observed of preterm delivery with UCI. In our study, 36 neonates had birth weight less than $2.5 \mathrm{~kg}$ out of which 6 had hypocoiled cords. Association of hypocoiling with low birth weight is statistically significant, with p-value 0.048 .

Table 3 reflects the statistical significance of meconium staining and hypocoiled cords with p-value 0.003 .

Eight babies had Apgar score at 1 minute of 7 or less, out of which 3 had hypocoiled cords, so it was statistically significant with a p-value of 0.002. Apgar score observed at 5 minutes was less than 7 in only one baby, who had normocoiling and so, it was not statistically significant (Table 4).

Table 2: Correlation between mode of delivery, preterm delivery, and birth weight of the neonate with $\mathrm{UCI}$

\begin{tabular}{|c|c|c|c|c|c|}
\hline & Normal & Hуро & $p$-value & Hyper & $p$-value \\
\hline \multicolumn{6}{|l|}{ Mode of delivery } \\
\hline Vaginal delivery & $66(81.48 \%)$ & $6(66.66 \%)$ & 0.29 & $8(80 \%)$ & 0.90 \\
\hline LSCS & $15(18.52)$ & $3(33.34 \%)$ & & $2(20 \%)$ & \\
\hline Total & $81(100 \%)$ & $9(100 \%)$ & & $10(100 \%)$ & \\
\hline \multicolumn{6}{|l|}{ Duration } \\
\hline Preterm & $13(16.04 \%)$ & $3(33.33 \%)$ & 0.19 & $1(1 \%)$ & 0.61 \\
\hline Term & $68(83.96 \%)$ & $6(66.67 \%)$ & & $9(9 \%)$ & \\
\hline Total & $81(81 \%)$ & $9(9 \%)$ & & $10(10 \%)$ & \\
\hline \multicolumn{6}{|l|}{ Birth weight } \\
\hline$<2.5$ & $27(33.33 \%)$ & $6(66.66 \%)$ & 0.048 & $3(30 \%)$ & 0.83 \\
\hline $2.5-4.0$ & $54(66.66 \%)$ & $3(33.34 \%)$ & $7(70 \%)$ & & \\
\hline Total & $81(100 \%)$ & $9(100 \%)$ & $10(100 \%)$ & & \\
\hline
\end{tabular}

Table 3: Association of meconium staining with UCI

\begin{tabular}{|c|c|c|c|c|c|}
\hline Meconium staining & Normal & Hуро & $p$-value & Hyper & $p$-value \\
\hline Yes & $8(9.87 \%)$ & $4(44.44 \%)$ & 0.003 & $2(20 \%)$ & 0.33 \\
\hline No & $73(90.13 \%)$ & $5(55.55 \%)$ & & $8(80 \%)$ & \\
\hline Total & $81(100 \%)$ & $9(100 \%)$ & & $10(100 \%)$ & \\
\hline
\end{tabular}

Table 4: Association of Apgar score at 1 minute, 5 minutes, and NICU admission with UCI

\begin{tabular}{|c|c|c|c|c|c|}
\hline & Normal & Hypocoiling & $p$-value & Hypercoiling & $p$-value \\
\hline \multicolumn{6}{|c|}{ Apgar score at 1 minute } \\
\hline$<7.0$ & $4(4.93 \%)$ & $3(33.33 \%)$ & 0.002 & $1(1 \%)$ & 0.50 \\
\hline$>7.0$ & $77(95.07 \%)$ & $6(66.67 \%)$ & & $9(9 \%)$ & \\
\hline Total & $81(100 \%)$ & $9(100 \%)$ & & $10(100 \%)$ & \\
\hline \multicolumn{6}{|c|}{ Apgar score at 5 minutes } \\
\hline$<7$ & $1(1.21 \%)$ & 0 & 0.72 & 0 & 0.72 \\
\hline$>7$ & $81(98.79 \%)$ & $9(100 \%)$ & & $10(100 \%)$ & \\
\hline Total & $82(100 \%)$ & $9(100 \%)$ & & $10(100 \%)$ & \\
\hline \multicolumn{6}{|c|}{ NICU admission } \\
\hline Yes & $4(4.93 \%)$ & $3(33.33 \%)$ & 0.002 & $0(0 \%)$ & 0.47 \\
\hline No & $77(95.07 \%)$ & $6(66.67 \%)$ & & $10(100 \%)$ & \\
\hline Total & $81(100 \%)$ & $9(100 \%)$ & & $10(100 \%)$ & \\
\hline
\end{tabular}


Among 7 NICU admissions, 4 had normocoiling, 3 hypocoiling, and none hypercoiled cords. Association of NICU admissions with hypocoiling was statistically significant with $p$-value of 0.002 .

\section{DISCUSSION}

The primary goal of antenatal evaluation is to identify fetuses at risk for intrauterine injury and death, and hence, intervention and timely delivery can prevent progression to stillbirth.

The mean UCI in our study was $0.61 \pm 0.16$. It was higher as compared with other studies done in the past.

There may be a possibility of a dynamically evolving UCI with advancing gestational age. Most of the patients recruited in other studies were in the early gestational age, whereas we have recruited most of our patients in advanced gestational age.

No significant association was observed between $\mathrm{UCI}$ and age of the patient. Findings are consistent with those of Feyl-Woboso and Omo-Aghoja. ${ }^{9}$ However, this is different than the study by Chitra et $\mathrm{al}^{10}$ who found an association between elderly gravida (35 years) and both hypocoiled and hypercoiled cords. Ezimokhai et $\mathrm{al}^{7}$ also found hypercoiled cords to be associated with extremes of maternal age. This is in contrast to our study in which all patients recruited were less than 35 years as our hospital treats rural and poor population who marry and conceive at an early age.

Correlation of UCI with gravidity in our study did not show any statistical significance, which is inconsistent with the study by Chitra et al. ${ }^{10}$

Association of UCI with mode of delivery was studied and is statistically not significant. This is consistent with the study done by Strong et $\mathrm{al}^{5}$ who showed no association of UCI with mode of delivery. However, this is different than the study of Rana et $\mathrm{al}^{11}$ and De Laat et $\mathrm{al}^{12}$ who found association of cesarean section with hypocoiling.

Low birth weight was associated with hypocoiling which is statistically significant with a p-value of 0.048 , whereas no statistically significant association of hypercoiling with low birth weight was observed in our study. This is comparable to the study of Chitra et $\mathrm{al}^{10}$ in which birth weight of the babies was compared with UCI and it was found that low birth weight, i.e., $<2.5 \mathrm{~kg}$, was significantly associated with both hypocoiled and hypercoiled cords. Studies by Rana et al, ${ }^{11}$ and De Laat et $\mathrm{al}^{12}$ have also shown an association of hypercoiling and low birth weight. This is in contrast to findings of our study in which no association of low birth weight with hypercoiling was observed.
Strong et $\mathrm{al}^{5}$ and De Laat et $\mathrm{al}^{12}$ showed association of preterm labor and hypocoiling, whereas Rana et $\mathrm{al}^{11}$ found hypercoiling to be significantly associated with preterm labor. They believed that hyprecoiling was an adaptive response to fetal hemodynamic changes, which initiates preterm labor on reaching a certain threshold. But no statistically significant association between preterm labor and hypocoiling or hypercoiling was observed in our study. In our study, 17 patients had preterm deliveries out of which only 3 had hypocoiled cords and 1 hypercoiled cord. Out of the remaining 13 cases, maximum had bacterial vaginosis as a cause for preterm labor.

Association of meconium staining with hypocoiling is statistically significant with a p-value of 0.003 . The results are similar to the study by Gupta et al. ${ }^{13}$ They studied 107 umbilical cords and found that in the hypocoiled group, meconium staining was significantly higher than in those with normocoiled cords. The findings are also consistent with the study by Strong et al ${ }^{5}$ where 100 cases were studied, and they found that meconium staining was associated with UCI values less than 10th percentile with p-value of 0.03 , which is highly significant. Padmanabhan et $\mathrm{al}^{14}$ also studied 130 cases, where they found that meconium staining was significant among hypocoiled cords. The mechanism by which this could be mediated includes the possibility that undercoiled cords may be more susceptible to acute kinking and therefore abrupt and marked cessation of blood flow.

Association of UCI with Apgar score at 1 minute was studied and has shown an association of low Apgar score with hypocoiled cords, which is statistically significant with a p-value of 0.002 . This is inconsistent with a similar study by Gupta et $\mathrm{a}^{13}$ who studied 107 umbilical cords and found that in hypocoiled cords, low Apgar score at 1 minute was present. In another study by Padmanabhan et $\mathrm{al}_{,}{ }^{14} 130$ umbilical cords were studied and it was observed that in hypocoiled cords, there was significant low Apgar score.

Apgar score at 5 minutes and its association with $\mathrm{UCI}$ were also studied, but we did not find any statistically significant correlation. This was not consistent with the study by De Laat et $\mathrm{al}^{12}$ who studied 885 patients and found that hypocoiling was associated with low Apgar score less than 7 at 5 minutes. Gupta et $\mathrm{al}^{13}$ found that babies with Apgar scores of $<7$ had significantly lower UCIs than those with Apgar scores of $>7$. Padmanabhan et $\mathrm{al}^{14}$ studied 130 umbilical cords and found that hypocoiling was associated with low Apgar score of $<7$ at 5 minutes.

Good Apgar score at 5 minutes in our study may be due to timely intervention, as all cases were monitored by continuous cardiotocography (CTG) and hence there is no prolonged hypoxia in utero and immediate 
effective resuscitation improved the babies' Apgar score at 5 minutes, as they never went into secondary apnea.

The NICU admission with hypocoiling was statistically significant with a p-value of 0.002 . Our study is consistent with a similar study conducted by De Laat et $\mathrm{al}^{12}$ who studied 885 cases and concluded that hypocoiling of the cord was associated with fetal distress and NICU admissions. Strong et $\mathrm{al}^{5}$ found that incidence of fetal death in the noncoiled group was significantly greater.

With this study, it is inferred that UCI seems to be a reliable screening test for assessing fetal well-being in utero. In patients with no obvious risk factors, having hypocoiled cords was associated with poor neonatal outcome. So, this identifies the subset of patients and underscores the need for vigorous monitoring.

\section{CONCLUSION}

There was a statistical significance of hypocoiling with low birth weight. So, antenatal UCI cases having hypocoiled cords require close antenatal monitoring by Doppler studies. Significantly higher incidence of meconium staining was observed with hypocoiled cords, requiring further close monitoring by CTG and so early artificial rupture of membranes is required in cases of abnormal UCI. Correlation of low Apgar score at 1 minute and NICU admissions with abnormal UCI identifies fetus at risk and fetal jeopardy and need for close intrapartum monitoring to have better perinatal outcome.

Larger controlled trials are required to prove the efficacy of antenatal UCI. However, further evaluation by scalp blood sampling and fetal pulse oxymetry may help in improving perinatal outcome.

\section{REFERENCES}

1. Ferguson VL, Dodson RB. Bioengineering aspects of the umbilical cord. Eur J Onstet Gynecol Reprod Biol 2009;144 (Suppl 1):S108-S113

2. Van Dijk CC, Franx A, de Laat MWM, Bruinse HW, Visser GHA, Nikkels PGJ. The umbilical coiling index in normal pregnancy. J Matern Fetal Neonatal Med 2002 Apr;11(4):280-283.

3. Edmonds HW. The spiral twist of the normal umbilical cord in twins and in singletons. Am J Obstet Gynaecol 1954 Jan;67(1):102-120.

4. Maplas P, Symonds EM. Observation on the structure of the human umbilical cord. Surg Obstet Gynecol 1966;123:746-750.

5. Strong TH, Jarles DL, Vega JS. The umbilical coiling index. Am J Obst Gynaecol 1994 Jan;170(1 Pt 1):29-32.

6. Machin GA, Ackerman J, Gilbert-Barness E. Abnormal cord coiling is associated with adverse perinatal outcomes. Paediatr Dev Pathol 2000 Sep-Oct;3(5):462-471.

7. Ezimokhai M, Rizk DE, Thomas L. Abnormal vascular coiling of the umbilical cord in gestational diabetes mellitus. Arch Physiol Biochem 2001 Jul;109(3):209-214.

8. Ercol T, Lacin S, Altunyurt S, Saygili U, Cinar O, Mumcu A. Umbilical coiling index: is it a marker for the foetus at risk? Br J Clin Pract 1996 Jul:50(5):254-256.

9. Feyl-Woboso PA, Omo-Aghoja LO. Umbilical cord coiling index in women of south eastern Nigeria. J Womens Health Issues Care 2014;3(4).

10. Chitra T, Sushanth YS, Raghuvan S. Umbilical coiling index as a marker of perinatal outcome: an analytical study. Obst Gynaecol Int 2012;Article ID 213689:1-6.

11. Rana J, Ebert GA, Kappy KA. Adverse perinatal outcome in patients with an abnormal umbilical coiling index. Obstet Gynaecol 1995 Apr;85(4):573-577.

12. De Laat WM, Frank A, Bots M, Visser GH, Nikkels PG. Umbilical coiling index in normal and complicated pregnancies. Obstet Gynecol 2006 May;107(5):1049-1055.

13. Gupta S, Faridi MMA, Krishnan J. Umbilical coiling index. J Obstet Gynaecol 2006 Jul-Aug;56(4):315-319.

14. Padmanabhan LD, Mheskar R, Mheskar A. Umbilical vascular coiling and perinatal outcome. J O Obstet Gynaecol India 2001;51(6):45-44. 